\title{
PENANGANAN GANGGUAN REPRODUKSI UNTUK MENINGKATKAN EFISIENSI REPRODUKSI PADA SAPI PERAH MENUJU SWASEMBADA SUSU DI KECAMATAN SENDANG KABUPATEN TULUNGAGUNG
}

\section{(REPRODUCTIVE DISORDER TREATMENTS FOR REPRODUCTION EFFICIENCY IMPROVEMENTS IN DAIRY CATTLE TO ACHIEVE MILK SELF-SUFFICIENCY AT SENDANG DISTRICT TULUNGAGUNG)}

\author{
Hermin Ratnani ${ }^{1}$, Dewa Ketut Meles ${ }^{2}$, dan Imam Mustofa ${ }^{3}$ \\ ${ }^{1,3}$ Departemen Reproduksi Veteriner, ${ }^{2}$ Departemen Kedokteran Dasar Fakultas \\ Kedokteran Hewan Universitas Airlangga \\ e-mail: herminratnani@yahoo.com
}

\begin{abstract}
The aims of local public community partnership program (PKM) with Sumber Makmur Group 3 conducted in Sendang was to :1). Improve the capability of each farmer on treating the cattle 2). Reduce the risk of reproductive disorders which has impact on the insemination 3). Increase the calf-born and milk yield 4). Efficiency in dairy cattle management and 5). Efficiency in feed cost followed by the improved production and reproduction rate in the dairy cattle management. The method used in this partnership program was through training which offer a guidance to farmer the basic information about reproductive disorder also their prevention necessity, and Treatments to the target cattle and also a supplementation of multivitamin to reduce the risk of any reproductive disorders. The program was conduted by 3 veterinary medicine staff from Airlangga university assisted by 2 local people and PPDH-PKL students. The 3 staff of veterinary medicine picked were an expert in reproduction, artificial insemination, and health department as well as an expert in housing and sanitary in dairy cattle management. The program was evaluated by the effectiveness of the training program by using a pre and post test for each individual farmer that was participated. The administered treatments and the reproductive efficiency were also recorded as a comparison before and after the program to show whether it has significant positive or negative result. The evaluation shown a result of each farmer with average pre-test score $58,24 \%$ to $77,06 \%$ on post-test $(32,31 \%)$. The reproductive disorders case was reported to have been reduced from 95 to $18(81,05 \%)$. The reproductive efficiency also shown a positive result whereas the Service per conception $(\mathrm{S} / \mathrm{C})$ before the program was reduced from $>2-3$ times to less than 2 times after the program followed with the service period from 2-3 month into 2 months. The Calving Rate (CR) was also reported to have increased from $<50 \%$ to $>50 \%$ after the program.
\end{abstract}

Keywords: Reproductive, Disorders, Prevention, Treatments, Supplementation

\begin{abstract}
abstrak
Tujuan dari program kemitraan masyarakat publik lokal (PKM) dengan Sumber Makmur Group 3 yang dilakukan di Sendang adalah untuk: 1). Tingkatkan kemampuan masing-masing petani dalam merawat ternak 2). Mengurangi risiko gangguan reproduksi yang berdampak pada inseminasi 3). Meningkatkan kelahiran anak sapi dan produksi susu 4). Efisiensi dalam pengelolaan sapi perah dan 5). Efisiensi biaya pakan diikuti oleh peningkatan produksi dan tingkat reproduksi dalam manajemen sapi perah. Metode yang digunakan dalam program kemitraan ini adalah melalui pelatihan yang menawarkan panduan kepada petani informasi dasar tentang gangguan reproduksi serta kebutuhan pencegahan mereka, dan Perawatan untuk ternak target dan juga suplemen multivitamin untuk mengurangi risiko gangguan reproduksi. Program ini disetujui oleh 3 staf kedokteran hewan dari universitas Airlangga dibantu oleh 2 orang lokal dan mahasiswa PPDH-PKL. Tiga staf kedokteran hewan yang dipilih adalah
\end{abstract}


seorang ahli dalam bidang reproduksi, inseminasi buatan, dan departemen kesehatan serta seorang ahli dalam bidang perumahan dan sanitasi dalam manajemen sapi perah. Program ini dievaluasi dengan efektivitas program pelatihan dengan menggunakan tes sebelum dan sesudah untuk masing-masing petani yang berpartisipasi. Perawatan yang diberikan dan efisiensi reproduksi juga dicatat sebagai perbandingan sebelum dan sesudah program untuk menunjukkan apakah itu memiliki hasil positif atau negatif yang signifikan. Evaluasi menunjukkan hasil dari masing-masing petani dengan skor pre-test rata-rata 58,24\% sampai $77,06 \%$ pada post-test $(32,31 \%)$. Kasus gangguan reproduksi dilaporkan telah berkurang dari 95 menjadi $18(81,05 \%)$. Efisiensi reproduksi juga menunjukkan hasil positif dimana Layanan per konsepsi (S / C) sebelum program berkurang dari> 2-3 kali menjadi kurang dari 2 kali setelah program diikuti dengan periode layanan dari 2-3 bulan menjadi 2 bulan. Tingkat Calving (CR) juga dilaporkan telah meningkat dari $<50 \%$ menjadi $>50 \%$ setelah program.

Kata kunci: Reproduksi, Gangguan, Pencegahan, Perawatan, Suplementasi

\section{PENDAHULUAN}

Usaha peternakan sapi perah di Indonesia sampai saat ini masih menghadapi berbagai kendala, yang berdampak pada produktivitas ternak. Sebagian besar kendalanya adalah masih tingginya kaus gangguan reproduksi seperti anestrus. Akibatnya, efisiensi reproduksi rendah dan kelambanan perkembangan populasi ternak. Dengan demikian perlu adanya pengelolaan ternak yang baik agar daya tahan reproduksi meningkat sehingga menghasilkan efisiensi reproduksi tinggi yang diikuti dengan produktivitas ternak yang tinggi pula (Hayati dan Choliq, 2009).

Swasembada susu merupakan salah satu program di Indonesia yang bertujuan sebagai penunjang pemenuhan kebutuhan nutrisi di masyarakat. Tingginya populasi masyarakat di Indonesia diikuti dengan peningkatan kebutuhan nutrisi khususnya pada susu. Fakta menunjukkan bahwa target swasembada pada tahun 2020 mengalami kendala dikarenakan oleh pertumbuhan populasi ternak sapi perah tidak berbanding lurus dengan produksi susu dalam negri. Kebutuhan susu di Indonesia mencapai 4,45 juta ton per tahun dengan produksi susu dalam negri diperoleh sekitar 920 ribu ton pada tahun 2018.

Kendala tersebut dipengaruhi oleh berbagai faktor salah satunya adalah reproduksi. Gangguan reproduksi pada sapi perah dipengaruhi oleh tingkat negative energy balance (NEB) pada ternak yang merupakan salah satu pemicu gangguan metabolisme seperti ketosis, displaced abomasum, retensio placenta, dan tingkat kerentanan ternak sapi perah terhadap infeksi (Grummer et al., 2004). Hal tersebut dapat mengakibatkan tidak hanya penurunan produksi susu pada sapi perah, namun juga menurunkan angka kelahiran (Calving rate), terjadinya Repeat breeder, dan ternak menjadi steril yang berdampak pada kerugian pada peternak (Maaruf et al., 2012). Penaganan ternak sebelum dan sesudah ternak melahirkan merupakan salah satu kunci dalam suksesnya swasembada susu di Indonesia.

Permasalahan yang paling mendasar pada peternakan sapi perah di Indonesia adalah masih rendahnya efisiensi reproduksi. Efisiensi reproduksi sapi perah dapat dilihat dari berbagai parameter salah satunya yaitu service per conception (S/C) (Fitrianti, 2003). S/C adalah penilaian atau perhitungan jumlah pelayanan (service) IB yang 
dibutuhkan oleh seekor betina sampai terjadi kebuntingan. Nilai S/C yang normal berkisar antara 1,6-2,0, semakin rendah nilai S/C berarti semakin tinggi nilai kesuburan betina tersebut dan sebaliknya (Toelihere, 1993). Kegagalan reproduksi sapi perah dapat diakibatkan oleh interaksi dari berbagai faktor, seperti pakan, lingkungan, keterampilan manusia dan manajemen pemeliharaan, gangguan fungsional (hormonal) dan penyakit (Bittar et al., 2014; Cruz et al., 2011). Optimalisasi efisiensi reproduksi sangat perlu yaitu untuk menjaga keberlangsungan dan perekonomian dalam bidang peternakan (Rodgers et al., 2012; Ribeiro et al., 2012). Kegagalan kebuntingan pada sapi adalah merupakan manifestasi utama gangguan efisiensi reproduksi (Mengistu and Wondimagegn, 2018). Walaupun tingkat kebehasilan fertilisasi diperkirakan diatas $80 \%$, namun potensi kegagalan zygot untuk bertahan hidup sampai dengan akhir minggu keempat dari perkembangannya adalah mencapai 50\% (Maaruf et al., 2012). Walaupun tidak sering, kematian fetus setelah kebuntingan umur 42 hari, adalah meurgikan dan secara signifikan mengurangi keuntungan (De Vries, A. 2006). Kondisi uterus yang suboptimal dan kompetensi embryo yang kurang adalah penyebab utama kegagalan, dan kondisi ini diakibatkan oleh beberapa faktor genetik dan non genetik maupun interaksinya. Inflamasi adalah penyakit radang telah diidentifikasi sebagai mayoritas penyebab kegagalan reproduksi pada sapi, yang sangat berpengaruh pada optimalnya reproduksi sapi. Evaluasi penyakit radang pada fertilitas ternak sapi, meliputi mekanisme potensi biologis dan yang berkaitan dengan dampak kesehatan dan managemen reproduksi.

Program PKM Simlitabmas Ristek Dikti dilakukan di wilayah desa Nglurup kecamatan Sendang kabupaten Tulungagung, dimana berdasarkan hasil survei di lokasi menunjukkan bahwa peternakan sapi perah di wilayah tersebut memiliki potensi yang tinggi dalam rangka pemenuhan kebutuhan susu atau swasembada susu nasional dengan ketersediaan hijauan pakan yang cukup melimpah. Kondisi umum daripada lokasi program PKM umumnya adalah daerah pegunungan dengan ketinggian tempat antara $450 \mathrm{~m}$ hingga $1150 \mathrm{~m}$ dari permukaan laut dengan rata-rata curah hujan $2611 \mathrm{~mm}$ per tahun. Mitra yang bekerja sama dalam program ini adalah kelompok tani ternak "Sumber Makmur III" yang mempunyai anggota sejumlah peternak sapi perah 69 orang. Total jumlah ternak sapi perah yang dimiliki yaitu sebesar 209 ekor (Laktasi bunting 45 ekor, laktasi tidak bunting 43 ekor, dara bunting 25 ekor, kering bunting 16 ekor, dara tidak bunting 60 ekor, dan pedet 20 ekor) dengan produksi susu sebesar 897 liter/hari.

Permasalahan yang masih perlu mendapat solusi yang dihadapi kelompok ternak adalah belum tercapainya angka efisiensi reproduksi yaitu S/C (Service/Conception) $>2$, Conception Rate $(\mathrm{CR})<50 \%$ yang disebabkan oleh masih tingginya kasus gangguan reproduksi (retensio sekundinarum, anestrus, repeat breeder, endometritis, pyometra, .abortus, hypofungsi ovarium, Corpus Luteum Persistent (CLP) yang berujung dengan kegagalan kebuntingan sehingga angka kelahiran rendah, produksi susu dan populasi menurun. Umumnya angka service per conception (S/C) yaitu 1-2, dimana pada penelitian sebelumnya diperoleh rata-rata 1,32 $\pm 0,03$ dan Conception rate (CR) sebesar 50-55\% dengan inseminasi pertama memiliki tingkat keberhasilan yang lebih tinggi dibandingkan dengan yang selanjutnya pada sapi perah Friesian Holstein (Hardjopranjoto, 1995; Mengistu and Wondimagegn, 2018). Faktor hijauan pakan pada musim kemarau juga menjadi 
permasalahan pokok untuk usaha sapi perah yang sebagian besar mengandalkan hijauan rumput yang tersedia di pegunungan.

\section{METODE PENGABDIAN MASYARAKAT}

Pelaksanaan kegiatan yang akan dilakukan antara lain: pendidikan dan pelatihan pada peternak dalam hal zooteknis peternakan (cara pemeliharaan, sanitasi kandang, mengenali tanda-tanda penyakit reproduksi, recording (pencatatan data), system pelaporan hewan sakit dan birahi). Pada level petugas lapangan (paramedis, inseminator, tenaga ATR) dilakukan penyegaran dalam bentuk pelatihan/ketrampilan dalam pelayanan gangguan reproduksi, sinkronisasi birahi, inseminasi buatan (IB), recording (data populasi ternak per triwulan), pengolahan limbah pertanian untuk pakan serta pemeriksaan dan pengobatan gangguan reproduksi) yang pelaksanaannya akan dilakukan secara bersama-sama petugas setempat, Tim PKM dan mahasiswa PKL.

Program pendidikan dan pelatihan pengenalan tanda-tanda gangguan reproduksi dan pengobatan gangguan reproduksi sapi perah di desa Nglurup kecamatan Sendang kabupaten Tulungagung ini dilakukan untuk mengatasi permasalahan 1). angka kebuntingan masih rendah < 40\%, 2). S/C (Service/Conception) atau Jumlah IB (Inseminasi Buatan) masih $>2$ kali 3) gangguan reproduksi meliputi kasus penyakit reproduksi masih tinggi 4). biaya produksi masih cukup tinggi, 5). pengetahuan dan ketrampilan peternak/petugas (paramedis, inseminator, ATR) masih rendah 6). kesulitan hijauan pakan di musim kemarau dan masih kurangnya pengetahuan teknologi pengolahan pakan dari pertanian.

Pelaksanaan program ini ditangani oleh 3 orang staf pengajar Fakultas Kedokteran Hewan Unair dibantu dengan 2 orang tenaga lokal (setempat) dan mahasiswa PPDH-PKL. Tenaga pengajar yang terlibat adalah ahli reproduksi, ahli Inseminasi Buatan (IB), ahli kesehatan reproduksi ternak serta ahli sanitasi dan perkandangan. Pada kesempatan ini pula telah diperkenalkan cara penggunaan obat-obatan (dosis) yang tepat sehingga tidak menimbulkan efek resistensi terhadap antibiotik khususnya yang dapat berdampak pada konsumen susu, sedangkan pemberian multivitamin ditujukan untuk memperkuat kondisi tubuh, mempercepat kesembuhan maupun pencegahan terhadap penyakit, terutama gangguan reproduksi.

Evaluasi keberhasilan PKM pada kelompok tani ternak "Sumber Makmur III" dicapai pada tahap I adalah 1). peningkatan pengetahuan peternak setelah dilakukan pendidikan dan pelatihan dan 2). Penurunan kasus gangguan reproduksi. Tahap II: Dengan keberhasilan pengobatan gangguan reproduksi diharapkan akan terjadi peningkatan angka kebuntingan. Pada akhir program dilakukan pemantauan langsung kelapangan untuk mengevaluasi peningkatan ketrampilan dalam hal cara pemeliharaan, sanitasi kandang, pemberian pakan.

\section{HASIL DAN PEMBAHASAN}

\section{Kasus Gangguan Reproduksi Dan Hasil Pengobatan}

Data hasil penanganan gangguan penyakit reproduksi di desa Nglurup kecamatan Sendang kabupaten Tulungagung dapat dilihat pada Tabel 1. 
Tabel 1. Data Kasus Gangguan Reproduksi

\begin{tabular}{llccc}
\hline \multirow{2}{*}{ No } & \multicolumn{1}{c}{ Nama Kasus } & Sebelum PKM & Sesudah PKM & $\begin{array}{c}\text { Persentase } \\
\text { Penurunan } \\
\text { Kasus (\%) }\end{array}$ \\
\hline 1. & Endometritis & 25 & 5 & $80 \%$ \\
2 & Pyometra & 10 & 2 & $80 \%$ \\
3. & Repeat breeder & 9 & 3 & $66,7 \%$ \\
4. & Hypofungsi ovarium & 10 & 5 & $50 \%$ \\
5. & Corpus Luteum Persisten & 10 & 3 & $70 \%$ \\
5. & Retensio sekundinarum & 9 & 0 & $0 \%$ \\
6. & Hypocalsemia & 12 & 0 & $0 \%$ \\
& Jumlah & 95 & 18 & $81,05 \%$ \\
\hline
\end{tabular}

Berdasarkan hasil data evaluasi pelaksanaan program PKM yaitu Pendidikan pelatihan dan pengobatan gangguan reproduksi pada ternak sapi perah diperoleh hasil penurunan jumlah kasus gangguan reproduksi yang cukup signifikan yaitu sekitar $81.05 \%$ dari total 95 kasus di lapangan. Tingginya kasus gangguan reproduksi terjadi dikarenakan beberapa faktor lain yaitu pada manajemen pemeliharaan ternak khususnya pakan dan sanitasi kandang, dimana keseimbangan nutrisi pakan sapi perah memiliki pengaruh terhadap performa reproduksi dan berkaitan erat dengan pencegahan gangguan reproduksi pada ternak (Bindari et al., 2013; Pradhan and Nakagoshi, 2008). Sanitasi kandang juga merupakan salah satu faktor penunjang keberhasilan dalam manajemen pemeliharaan nternak khususnya pada sapi perah. Sanitasi kandang merupakan suatu kegiatan pencegahan yang meliputi kebersihan bangunan tempat tinggal ternak atau kandang dan lingkungannya dalam rangka untuk menjaga kesehatan ternak sekaligus pemiliknya. Beberapa hal yang dapat mempengaruhi kondisi sanitasi kandang antara lain lokasi kandang, konstruksi bangunan kandang, dan kebersihan kandang. Buruknya sanitasi kandang pada peternakan sapi perah dapat meyebabkan kontaminasi pada susu dan berkembang biaknya bakteri yang dapat memicu penyakit serta gangguan reproduksi pada ternak (Cruz et al., 2011; Haile et al., 2014). Masih tingginya kasus gangguan reproduksi yaitu endometritis, pyometra, repeat cbreeder, hypofungsi ovarium, dan corpus luteum persiste, disebabkan oleh karena faktor pakan baik kualitas maupun kuantitas konsentrat dan hijauan serta sanitasi kandang yang masih belum memenuhi syarat.

Konstruksi kandang, letak kandang yang sangat berdekatan dengan hunian, frekuensi pembersihan kandang yang masih kurang, kondisi tersebut juga merupakan penyebab terjadinya gangguan reproduksi maupun kesehatan peternak karena masih tedapat beberapa kendala seperti konstruksi kandang yang tidak sesuai standart, pemberian pakan dengan rasio yang tidak sesuai, dan manajemen pemeliharaan yang kurang memadai. Standar konstruksi kandang untuk sapi perah berdasarkan pedoman Dirjen Peternakan Peraturan Menteri Pertanian No. 100/ Permentan/OT.140/7/2014 adalah konstruksi bangunan yang kuat, memiliki saluran dan drainase yang baik, kondisi kandang yang kering dan tidak tergenang air, kemiringan lantai 2-5 derajat (tidak licin, mudah dikeringkan dan diberikan karpet/matras sebagai pijakan), dan Luas kandang sesuai periode masing-masing ternak (Grummer et al., 2004). 
Kasus endometritis dan corpus luteum persisten yang terjadi pada kelompok tani ternak "Sumber Makmur III" merupakan kasus gangguan reproduksi yang tergolong cukup tinggi. Hal tersebut dikarenakan kurangnya penanganan ternak sapi perah setelah melahirkan, dimana ternak yang baru melahirkan sangat rentan terhadap infeksi uterus. Infeksi uterus menyebabkan terjadinya pembengkakan uterus yang diikuti dengan keluarnya cairan mengadung darah dan juga berpengaruh terhadap proses involusi uterus. Terganggunya proses involusi uterus karena infeksi dapat menyebabkan tidak terjadi luteolisis atau terbentuknya corpus luteum persisten, yang mempertahankan fungsinya dalam siklus estrus (Bittar et al., 2014; Struve et al., 2013).

Hipofungsi ovarium merupakan penurunan fungsi pada ovarium. Gejala klinis yang terjadi adalah anestrus yang berkepanjangan dikarenakan penurunan konsentrasi hormon LH dan FSH dalam ovarium. Solusi permasalahan yang dapat dilakukan adalah dengan melakukan perbaikan sistem manajemen pakan dengan memberikan hijauan dan konsentrat sesuai standar serta pemberian multivitamin untuk menunjang kebutuhan nutrisi dalam pakan (Widarini dkk., 2017; Hermadi dkk., 2017).

Jumlah pengeluaran (culling) sapi perah karena kawin berulang (repeat breeder) dapat dikurangi dan angka kebuntingan dapat meningkat yaitu dengan pelaksanaan inseminasi buatan yang benar untuk menghindari kegagalan fertilisasi, pengobatan infeksi uterus yang tepat, terapi hormon untuk meningkatkan keberhasilan fertilisasi dan menurunkan kematian embryo, dan melakukan inseminasi setelah dilakukan pemeriksaan klinis oh tenaga ahli inseminator (Drillich et al., 2006). Pada pelaksanaan PKM ini juga dilakukan program pencegahan dengan terapi antiseptik intra uterin post partus, pengobatan antibiotik intra uterin dan terapi hormonal secara intra uterin maupun injeksi intra muskuler, suplementasi dengan multivitamin sehingga terjadi penurunan jumlah kasus gangguan reproduksi dan peningkatan angka kebuntingan (efisiensi reproduksi).

Hal-hal yang perlu menjadi pertimbangan tentang, penggunaan antimicrobial secara intrauterine tidak selalu dapat menurunkan kejadian radang uterus atau metritis, maupun meningkatkan fertilitas (Lima, 2013). Oxytetracycline, yang sering digunakan untuk terapi intrauterine pada sapi yang menderita retensio plasenta, menghambat metalloproteinase (MMPs) yang esensial untuk perbaikan endometrium pada spesies lain, dapat mengganggu mekanisme penempelan plasenta normal, sedangkan penggunaan antibiotic secara sistemik adalah lebih menguntungkan pada kasus metritis disertai demam (Ismail, 2011). Terapi sapi yang hanya menderita retensio plasenta dan demam dapat mengurangi penggunaan antimikrobia yang tidak perlu (Drillich et al., 2006). Pengobatan retensio plasenta pada sapi selama 5 hari dengan $2.2 \mathrm{mg} / \mathrm{kg}$ of ceftiofur hydrochloride efektif untuk mencegah metritis apabila dibanding dengan estradiol cypionate atau tidak diobati, akan tetapi selanjutnya mengakibatkan terjadinya peningkatan performa reproduksi yang tidak signifikan (Risco and Hernandez, 2013).

\section{Efisiensi Reproduksi}

Hasil evaluasi efisiensi reproduksi ternak sapi perah di desa Nglurup kecamatan Sendang kabupaten Tulungagung dapat dilihat pada tabel 2. 
Data hasil evaluasi efisiensi reproduksi menunjukkan bahwa pelaksanaan program PKM dengan mitra kelompok tani ternak "Sumber Makmur III" terdapat perubahan yang positif pada S/C, Service Periode, dan CR (Conception Rate). Umumnya angka service per conception (S/C) yaitu 1-2, dimana pada penelitian sebelumnya diperoleh rata-rata 1,32 $\pm 0,03$ dan Conception rate $(\mathrm{CR})$ sebesar $50-55 \%$ dengan inseminasi pertama memiliki tingkat keberhasilan yang lebih tinggi dibandingkan dengan yang selanjutnya pada sapi perah Friesian Holstein $(8,13)$. Ternak sapi perah di Indonesia pada umumnya memiliki nilai S/C rata-rata 1,72-3,13 kali [27].

Tabel 2. Profil Data Efisiensi Reproduksi Ternak Sapi perah

\begin{tabular}{llccc}
\hline No & Periode & $\begin{array}{c}\text { S/C (Service per } \\
\text { Conception) }\end{array}$ & $\begin{array}{c}\text { SP (Service } \\
\text { Periode) }\end{array}$ & $\begin{array}{c}\text { CR (conception } \\
\text { Rate) }\end{array}$ \\
\hline 1 & Sebelum PKM & $>2-3 \mathrm{kali}$ & $.2-3 \mathrm{bln}$ & $<50 \%$ \\
2 & Sesudah PKM & $\leq 2 \mathrm{kali}$ & $2 \mathrm{bln}$ & $>50 \%$ \\
\hline
\end{tabular}

Data efisiensi reproduksi menunjukkan bahwa Service per conception (S/C) pada mitra kelompok tani ternak menunjukkan angka 2-3 kali sebelum dilakukan program PKM. Angka CR (Conception rate) sebelum program diperoleh angka kurang dari $50 \%$ yang merupakan hasil yang belum optimal. Hal tersebut dikarenakan oleh berbagai faktor diantaranya adalah terlambatnya laporan ternak yang birahi pada petugas lapangan atau inseminator, jarak tempuh ke lokasi peternakan yang relatif jauh, ketrampilan petugas lapangan dalam melakukan inseminasi buatan serta recording ternak yang belum memadai sebagai penunjang keberhasilan IB. Faktor biologis dan lingkungan juga memiliki pengaruh terhadap S/C pada perkawinan pertama setelah melahirkan (First Service Conception) yaitu BCS (Body Condition Score), paritas, umur, dan gangguan reproduksi (distokia, metritis, dan retensio plasenta) peri-post-partum pada sapi perah (Hayati dan Choliq, 2009).

Solusi permasalahan yang dilakukan pada program PKM adalah dengan memberikan pendidikan dan pelatihan pada peternak dalam hal zooteknis peternakan (cara pemeliharaan, sanitasi kandang, mengenali tanda-tanda penyakit reproduksi, recording (pencatatan data), sistem pelaporan hewan sakit dan birahi. Pada level petugas lapangan (paramedis, inseminator, tenaga ATR) dilakukan penyegaran dalam bentuk pelatihan/ketrampilan dalam pelayanan gangguan reproduksi, sinkronisasi birahi, inseminasi buatan (IB), recording (data populasi ternak per triwulan), pengolahan limbah pertanian untuk pakan serta pemeriksaan dan pengobatan gangguan reproduksi). Hasil pre dan post test pada peternak menunjukkan hasil peningkatan pengetahuan dan wawasan setelah dilakukan pelatihan yang tercermin dari hasil penilaian pre/post Test (dari 58,24 menjadi 77,06). Menurut hasil penelitian sebelumnya, bahwa peningkatan nilai $\mathrm{S} / \mathrm{C}$ antara lain dipengaruhi oleh bertambahnya pengetahuan peternak setelah pendidikan/pelatihan, dan pencegahan gangguan reproduksi (Sari dkk., 2016). Kemampuan dan keterampilan seorang peternak juga berpengaruh terhadap peningkatan mutu sapi perah baik dalam hal produksi dan reproduksi (Hayati dan Choliq, 2009), karena apabila peternak memiliki pengetahuan beternak yang baik, peternak akan mampu mengatasi kejadian-kejadian stress dan menjaga kesehatan sapi perah. Dengan adanya pendidikan dan pelatihan pada program PKM, disamping pengalaman pribadi berternak yang sudah berjalan juga memperoleh 
pengetahuan beternak, teknologi baru tatalaksana peternakan dan informasi terbaru lainnya yang sangat bermanfaat untuk peningkatan efisiensi reproduksi, sehingga masalah-masalah yang menyebabkan gangguan reproduksi dapat dicegah.

Oleh karena itu, perlu adanya keterpaduan program antara pencegahan dan management praktis untuk menurunkan kejadian stress metabolic dalam mengoptimalkan strategi peternakan sapi perah dan mencegah dampak negative dari penyakit gangguan reproduksi terutama uterus pada sapi perah (Lima, 2018).

\section{PENUTUP}

\section{Simpulan}

Pendidikan dan pelatihan terhadap gangguan reproduksi ternak sapi perah pada peternak dapat meningkatkan wawasan dan ketrampilan peternak. Khususnya peningkatan ketrampilan dalam tatalaksana peternakan, pencegahan gangguan reproduksi, dan deteksi/pelaporan birahi tepat waktu. Penanganan dan pengobatan serta program supplementasi multivitamin mampu mencegah dan menurunkan kasus gangguan reproduksi pada sapi perah di wilayah mitra kelompok tani ternak "Sumber Makmur III"

\section{Saran}

Kegiatan Program Kemitraan Masyarakat (PKM) dilakukan secara berkesinambungan untuk mempertahankan tingkat reproduktifitas ternak sehingga dapat membantu terwujudnya swasembada susu dan meningkatkan kesejahteraan peternak. Perlu adanya pihak mahasiswa yang terlibat sebagai pembelajaran dalam dunia peternakan dan kedokteran hewan tentang pentingnya pencegahan penyakit dalam manajemen pemeliharaan.

\section{UCAPAN TERIMAKASIH}

Terima kasih kepada Direktorat Riset dan Pengabdian Masyarakat. Direktorat Jenderal Penguatan Riset dan Pengembangan Kementerian Riset, Teknologi, dan Pendidikan Tinggi. Sesuai dengan Surat Perjanjian Pendanaan Pelaksanaan Program Pengabdian Masyarakat Tahun Anggaran 2017. Nomor: 004/SP2H/PPM/DRPM/V/2017. Mitra kelompok tani ternak "Sumber Makmur III" yang telah bekerja sama untuk mewujudkan keberhasilan program kemitraan masyarakat (PKM).

\section{DAFTAR PUSTAKA}

Bindari, Y.R., S. Shrestha, N. Shrestha, and T.N. Gaire. 2013. "Effects of Nutrition on Reproduction". Advances in Applied Science Research 4(1): 421-429.

Bittar, J.H., P.J. Pinedo, C.A. Risco, J.E. Santos, W.W. Thatcher, K.E. Hencken, S. Croyle, M. Gobikrushanth, C.C. Barbosa, A. Vieira-Neto, and K.N. Galvao. 2014. "Inducing Ovulation Early Postpartum Influences Uterine Health and Fertility in Dairy Cows. ” J. Dairy Sci. 97:3558-3569. 
Cruz, C.E.F., D.L. Raymundo, C. Cerva, S.P. Pavarini, A.G.C. Dalto, L.G. Corbellini, and D. Driemeier. 2011. Records of Performance and Sanitary Status from a Dairy Cattle Herd in Souther Brazil. Pesq.Vet.Bras. 31(1): 1-7.

Drillich, M., Reichert, U., Mahlstedt, M., et al. 2006. "Comparison Of Two Strategies For Systemic Antibiotic Treatment Of Dairy Cows With Retained Fetal Membranes: Preventive Vs. Selective Treatment.” J Dairy Sci 89(5):1502-8.

Fitrianti, A. T. 2003. "Penampilan Reproduksi Sapi Perah di Peternakan Sapi Perah Rakyat Wilayah Kerja KUD Mojosongo Kabupaten Boyolali, Jawa Tengah”. Skripsi.Fakultas Kedokteran Hewan Institut Pertanian Bogor. Bogor.

Grummer, M.M., Mashek D. G., and Hayilri A. 2004. "Dry Matter Intake and Energy Balance in the Transition Period". Vet. Clin. N. Am-food. Anim. Pract 20: 447-470.

Haile, A., Y. Tsegaye, and N. Tesfaye. 2014. "Assessment of Major Reproductive Disorders of Dairy Cattle in Urban and per Urban Area of Hosanna, Southern Ethiophia". Animal and Veterinary Science 2(5): 135-141.

Hardjopranjoto, S. 1995. Ilmu Kemajiran pada Ternak. University Airlangga Press, Surabaya.

Hayati, R.N. dan A. Choliq. 2009. "Gangguan Reproduksi, Salah Satu Penghambat Perkembangan Ternak Sapi (Studi Kasus di Desa Padomasan Kabupaten Batang)". Seminar Nasional Kebangkitan Peternakan. Semarang. 177-181

Hermadi, H.A., M. Hariadi, and S. Susilowati. 2017. "The Ovarian Hypofunction: A Case in Cow Management Therapy". Advances in Health Sciences Research 5: 311-316.

Ismail. Risna. 2011. Manajemen Pemberian Pakan Sapi Perah Dara. http://rismanismail2.wordpress.com/2011/10/16/manajemen-pemberian pakansapi-perah-sapi-dara/. Di akses pada tanggal 16 Januari 2016.

Lima, F.S. 2013. "Manipulating ovarian function and uterine ehath with the aim of improving fertility in dairy cattle". PhD Disseration.

Lima, F. 2018. "New Advances in the Management of Uterine Diseases". WCDS Advances in Dairy Technology 30: 283-295.

Maaruf, A.A., M.R. Islam, M.M. Rahman, M.M.U. Bhuiyan, and M. Shamsuddin. 2012. "Prevalence of Reproductive Disorders of Dairy Cows in Chittagong District of Bangladesh". Bangladesh Vet J 46(1-4): 11-18.

Mengistu, D.W., and K.A. Wondimagegn. 2018. "Evaluation of the Reproductive Performance of Holstein Friesian Dairy Cows in Alage ATVET College", Ethiopia. International Journal of Livestock 9(6): 131-139. 
Pradhan, R., and N. Nakagoshi. 2008. "Reproductive Disorders in Cattle due to Nutritional Status". Journal of International Development and Cooperation 14(1): 45-66.

Ribeiro, E.S., R.S. Bisinotto, M.G. Favoreto, L.T. Martins, R.L.A. Cerri, F.T. Silvestre, L.F. Greco, W.W. Thatcher, and J.E.P. Santos. 2012. "Fertility in Dairy Cows Following Presynchronization and Administering Twice the Luteolytic dose of Prostaglandin $\mathrm{F}_{2 \alpha}$ as one or two Injections in the 5-day Timed Artificial Insemination Protocol". Theriogenology 78(2): 273-284.

Ribeiro, S.S., J. Siffain, N.P. Polyzos, Arnan van de Vijver, L. van Landuyt, D. Stoop, H. Tournaye, and C. Blockeel. 2016. "To Delay or Not to Delay a Frozen Embryo Transfer after a Failed Fresh Embryo Transfer Attempt?" Crossmark 105(5): 1202-1207.

Risco, C.A., Hernandez, J. 2003. "Comparison of ceftiofur hydrochloride and estradiol cypionate for metritis prevention and reproductive performance in dairy cows affected with retained fetal membranes". Theriogenology 60(1): 47-58.

Rodgers, J.C., S.L. Bird, J.E. Larson, N. DiLorenzo, C.R. Dahlen, A. DiCostanzo, and G.C. Lamb. 2012. "An Economic Evaluation of Estrous Synchronization and Timed Artificial Insemination in Suckled Beef Cows". J. Anim.Sci 90: 4055-4062.

Sari, E. C., Madi Hartono, M., dan Sri Suharyati, S. 2016. "Faktor- Faktor Yang Memengaruhi Service Per Conception Sapi Perah Pada Peternakan Rakyat Di Provinsi Lampung”. Jurnal Ilmiah Peternakan Terpadu Vol. 4(4): 313 - 318.

Struve, K., K. Herzog, F. Magata, M. Piechotta, K. Shirasuna, A. Miyamoto, and H. Bollwein. 2013. "The Effect of Metritis on Luteal Function in Dairy Cows". BMC Veterinary Research 9: 244.

Toelihere. 1993. Inseminasi Buatan pada Ternak. Fakultas Kedokteran Hewan. Institut Pertanian Bogor. Angkasa. Bandung.

Widarini, N., I.R. Beda, dan A.D. Wijayanti. 2017.” Efektivitas Terapi Multivitamin, Obat Cacing dan Premiks pada Sapi Terdiagnosa Hipofungsi Ovarium di Wilayah Kecamatan Prambanan, Yogyakarta”. Jurnal Sain Veteriner 35(2): 230-235. 